\title{
Lung Cancer Coexisting with Pulmonary Tuberculosis: A Rare Case Report
}

\author{
Amanpreet Kaur, N. C. Kajal, Amit Goyal \\ Department of Chest and TB, GMC, Amritsar, Punjab, India
}

\section{Abstract}

Lung cancer and tuberculosis (TB) are common causes of morbidity and mortality in the world. TB is a serious public health problem in developing countries including India, bearing the highest burden. Lung cancer is also increasing everywhere in the globe with India having the highest mortality due to lung cancer in males. Both diseases coexist producing a diagnostic dilemma. The simultaneous or sequential presentation of pulmonary TB and lung cancer within the same patient has been reported in various case series and case-control studies, but the association between them is still controversial. TB is an important risk factor for developing carcinoma lung. The dormant bacilli may activate due to disturbed defense mechanisms. Pulmonary cancer mortality was also higher in patients developing TB, simultaneously or during treatment courses, than in those without. The diagnosis may be delayed and the patient's survival may be decreased. Pulmonary TB coexisting with lung cancer can mask the underlying disorder resulting in delay in diagnosis and management of cancer patients. Here, we present a rare and interesting case of a 52-year-old male who was diagnosed as a case of microbiologically confirmed pulmonary TB and squamous cell lung carcinoma at the same time.

Keywords: Pulmonary tuberculosis, squamous cell carcinoma, smoking

\section{INTRODUCTION}

Lung carcinoma (LC) is the leading cause of cancer-related death and one of the major public health problems worldwide. ${ }^{[1]}$ Tobacco smoking remains the most established cause of lung malignancy. Tuberculosis (TB) is an important cause of morbidity and mortality despite good prevention, diagnosis, and effective therapy, especially in the poor and developing countries. ${ }^{[1,2]}$ There is a certain connection between pulmonary TB and lung or bronchial carcinoma, as it has been verified by many pathologists and clinicians. The association between these two diseases has great significance, since both are quite prevalent and have a serious impact on public health. Either of them can be primary or secondary. ${ }^{[3,4]}$ The two diseases may occur as follows:

a. Carcinoma occurs on the TB ground, reactivating the old focus of $\mathrm{TB}$

b. Carcinoma develops from previous TB scars (scar carcinoma)

c. Carcinoma developing by epithelium metaplasia of tuberculous cavities

d. Both diseases are independent of each other and develop simultaneously or sequentially by chance

\begin{tabular}{|l|l|}
\hline \multicolumn{2}{|c|}{ Access this article online } \\
\hline Quick Response Code: & Website: \\
\hline & www.ijrc.in \\
\hline & \\
\hline
\end{tabular}

e. Metastatic carcinoma developing in an old TB lesion

f. Secondary infection of TB in a cancer patient. ${ }^{[3-5]}$

\section{Case Report}

A 52-year-old male presented with complaint of breathlessness, productive cough and fever for 1 month, and chest pain for 7 days. There was an associated history of loss of appetite, generalized body weakness, and weight loss for 1 month. There was no complaint of palpitations or hemoptysis. There was no history of any chronic illness in the past including diabetes or hypertension. The patient was a chronic smoker with 30 pack-year smoking history and a chronic alcoholic.

On examination, the patient was moderately built. Pallor and clubbing were present. His oxygen saturation was $98 \%$ on

Address for correspondence: Dr. Amanpreet Kaur, Department of Chest and TB, GMC, Amritsar, Punjab, India. E-mail:ak1210.ap@gmail.com

This is an open access journal, and articles are distributed under the terms of the Creative Commons Attribution-NonCommercial-ShareAlike 4.0 License, which allows others to remix, tweak, and build upon the work non-commercially, as long as appropriate credit is given and the new creations are licensed under the identical terms.

For reprints contact: WKHLRPMedknow_reprints@wolterskluwer.com

How to cite this article: Kaur A, Kajal NC, Goyal A. Lung cancer coexisting with pulmonary tuberculosis: A rare case report. Indian J Respir Care 2021;10:126-8.

Received: $25-07-2020$

Accepted: 05-09-2020

Revised: $05-08-2020$ Published: 31-01-2021 
room air, respiratory rate $30 / \mathrm{min}$, and pulse rate $88 / \mathrm{min}$. There were no palpable lymph nodes. On auscultation, breath sounds were decreased on the right side and there were bilateral coarse crepitations.

Laboratory investigations showed a hemoglobin of $90 \mathrm{~g} / \mathrm{L}$, total leukocytes count $9.6 \times 10^{9}$ cells $/ \mathrm{mm}^{3}$, differential leukocyte count $70 \%$ neutrophils, $28 \%$ lymphocytes, and $2 \%$ eosinophils. The erythrocyte sedimentation rate was $130 \mathrm{~mm} / \mathrm{h}$. The liver and renal function tests were within normal limits. Sputum for acid-fast bacilli was negative. Sputum for CBNAAT (GeneXpert) showed Mycobacterium TB and it was "Rifampicin" sensitive.

Chest X-ray [Figure 1] showed heterogeneous opacity involving the middle and lower zone on the right side, upper zone on the left side with mediastinal widening. Ultrasound examination of the abdomen was grossly normal.

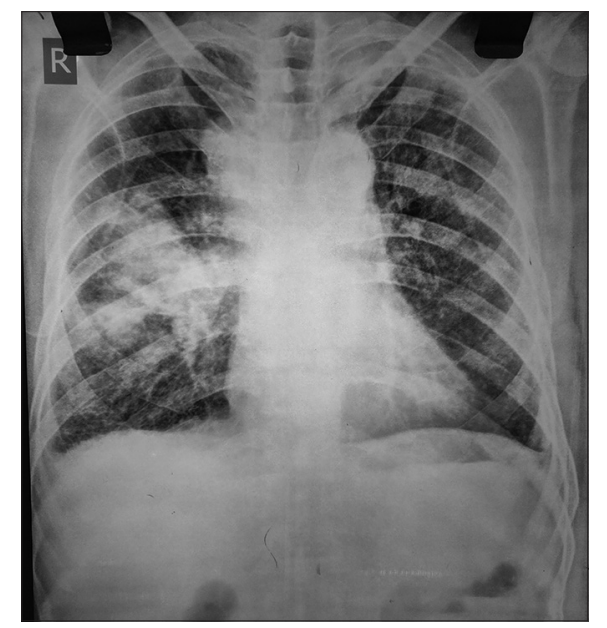

Figure 1: Contrast-enhanced computed tomography X-ray shows heterogenous opacity involving the right middle and lower zone and heterogenous opacity on the left side involving the upper zone with mediastinal widening

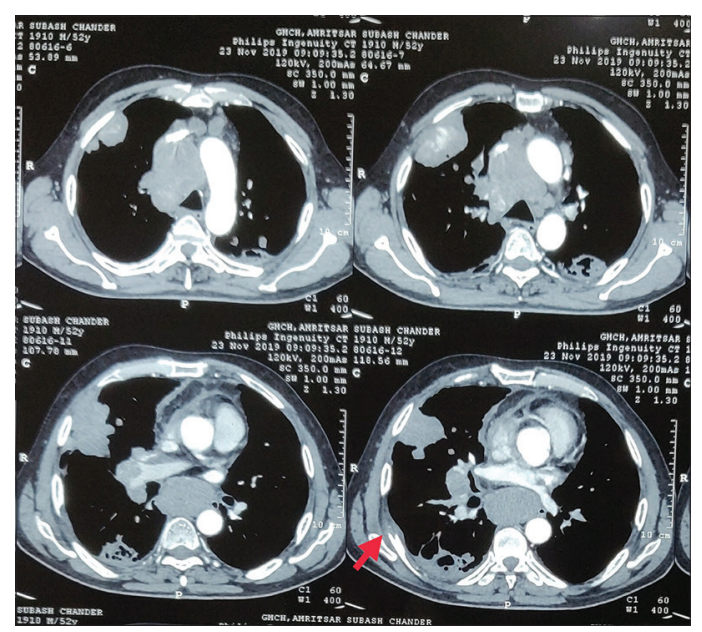

Figure 3: Contrast-enhanced computed tomography of the chest revealed homogeneously enhancing right pulmonary masses with areas of calcification with bilateral consolidation and cystic change, massive supraclavicular, mediastinal, and right hilar calcified lymphadenopathy, a large homogenous expansile destructive lesion in $9^{\text {th }}$ rib posteriorly (arrow)
Contrast-enhanced computed tomography of the chest [Figures 2 and 3] revealed homogeneously enhancing right pulmonary masses with areas of calcification with bilateral consolidation and cystic change, massive supraclavicular, mediastinal, and right hilar-calcified lymphadenopathy, a large homogenous expansile destructive lesion in $9^{\text {th }}$ rib posteriorly.

Computed tomography-guided fine-needle aspiration cytology [Figure 4] showed few clusters of malignant epithelial cells with squamous morphology; appearance indicating squamous cell carcinoma.

The patient was diagnosed to have squamous cell LC with coexisting pulmonary TB. He was advised antitubercular treatment and referred to the oncology department for chemotherapy and radiotherapy.

\section{Discussion}

Clinicians sometimes encounter patients with concurrent existence of LC and pulmonary TB. The coexistence of pulmonary $\mathrm{TB}$ and $\mathrm{LC}$ has remained controversial. These patients may have LC and develop active pulmonary TB

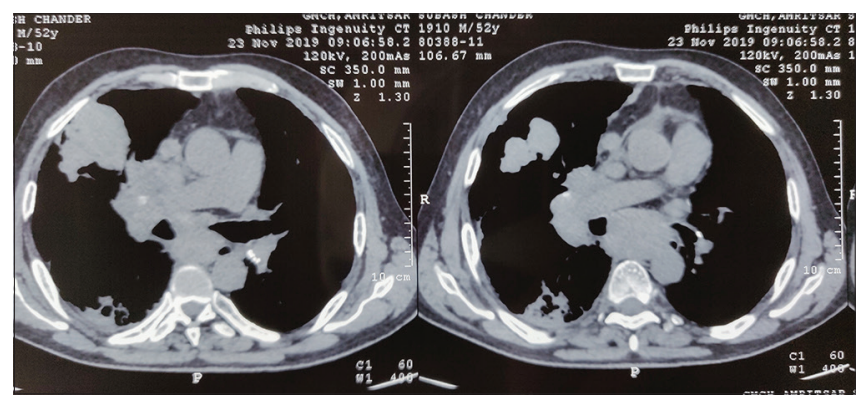

Figure 2: Contrast-enhanced computed tomography of the chest revealed homogenously enhancing right pulmonary masses with areas of calcification with bilateral consolidation and cystic changes; massive supraclavicular, mediastinal, and right hilar calcific lymphadenopathy

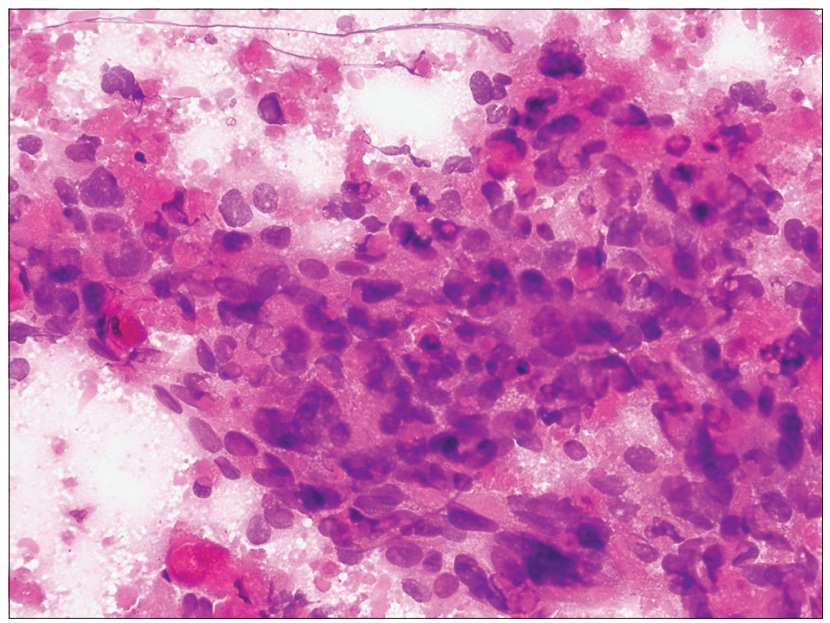

Figure 4: Fine-needle aspiration cytology of lung mass: clusters of malignant epithelial cells with squamous morphology. The cells have scanty to moderate cytoplasm and round to pleomorphic and hyperchromatic nuclei against a necrotic + keratinous looking background. The appearance indicates squamous cell carcinoma 
during treatment or carcinoma may develop in patients previously treated for TB. The coexistence of both diseases in the same patient may delay the diagnosis. Patients with lung cancer are vulnerable to develop active TB because of immunosuppression induced by the use of intensive treatment modalities, such as aggressive chemotherapy, radiotherapy, or malnutrition. ${ }^{[5]}$ Pulmonary TB and LC mimic each other with clinical and radiological similarities. The common symptoms in both are fever, loss of appetite, weight loss, fatigue, chest pain, hemoptysis, etc., Cancer cells may invade healed TB lesions in the lung and may lead to TB reactivation by weakening the local immunity. Two diseases may be present in the ipsilateral lung, contralateral lung, or same lobe location. Tuberculous bacilli may live at a dormant status in granulomas and induce TB sensitivity. ${ }^{[6]}$ If the local immunity is deteriorated, reactivation of a latent $\mathrm{TB}$, primary mycobacterial infection, or new exogenous infection may cause TB infection. ${ }^{[7,8]}$ This patient was a chronic smoker which may have been the cause of squamous cell carcinoma lung, but the coexistence and simultaneous diagnosis of LC and microbiologically confirmed TB was unique.

\section{Conclusion}

The coexistence of LC and pulmonary TB should be considered when a long-term smoker patient presents with symptoms of cough, expectoration, hemoptysis, fever, and chest pain. Thus, clinicians must be aware of the protean manifestations of TB and cancer and keep a high index of suspicion for simultaneous and/or misleading clinical and radiological presentations. Early TB diagnosis and antitubercular treatment may extend median survival in cancer. Our patient was antitubercular treatment and was referred to the oncology department for further management of LC.

\section{Declaration of patient consent}

The authors certify that they have obtained all appropriate patient consent forms. In the form, the patient has given his consent for his images and other clinical information to be reported in the journal. The patient understands that his name and initials will not be published and due efforts will be made to conceal the identity, but anonymity cannot be guaranteed.

\section{Financial support and sponsorship}

Nil.

\section{Conflicts of interest}

There are no conflicts of interest.

\section{RefEREnCES}

1. Silva DR, Valentini DF Jr., Müller AM, de Almeida CP, Dalcin Pde T. Pulmonary tuberculosis and lung cancer: Simultaneous and sequential occurrence. J Bras Pneumol 2013;39:484-9.

2. Liang HY, Li XL, Yu XS, Guan P, Yin ZH, He QC, et al. Facts and fiction of the relationship between preexisting tuberculosis and lung cancer risk: A systematic review. Int J Cancer 2009;125:2936-44.

3. Tanvetyanon T, Ratanatharathorn V, Leopairat J. Mucoepidermoid carcinoma of the lung presenting as a cavitary lesion. J Med Assoc Thai 2004;87:988-91.

4. Yilmaz A, Güngör S, Damadoğlu E, Aksoy F, Aybatli A, Düzgün S. Coexisting bronchial carcinoid tumor and pulmonary tuberculosis in the same lobe: A case report. Tuberk Toraks 2004;52:369-72.

5. Harikrishna J, Sukaveni V, Kumar DP, Mohan A. Cancer and tuberculosis. J Indian Acad Clin Med 2012;13:142-4.

6. Tamura A, Hebisawa A, Hayashi K, Sagara Y, Kawabe Y, Nagayama N, et al. Lung cancer in patients who had received thoracoplasty for pulmonary tuberculosis. Jpn J Clin Oncol 1999;29:541-5.

7. Karnak D, Kayacan O, Beder S. Reactivation of pulmonary tuberculosis in malignancy. Tumori 2002;88:251-4.

8. Cicènas S, Vencevičius V. Lung cancer in patients with tuberculosis. World J Surg Oncol 2007;5:1-5. 